\title{
El nicho ecológico de la paleobiología en el Patrimonio Histórico
}

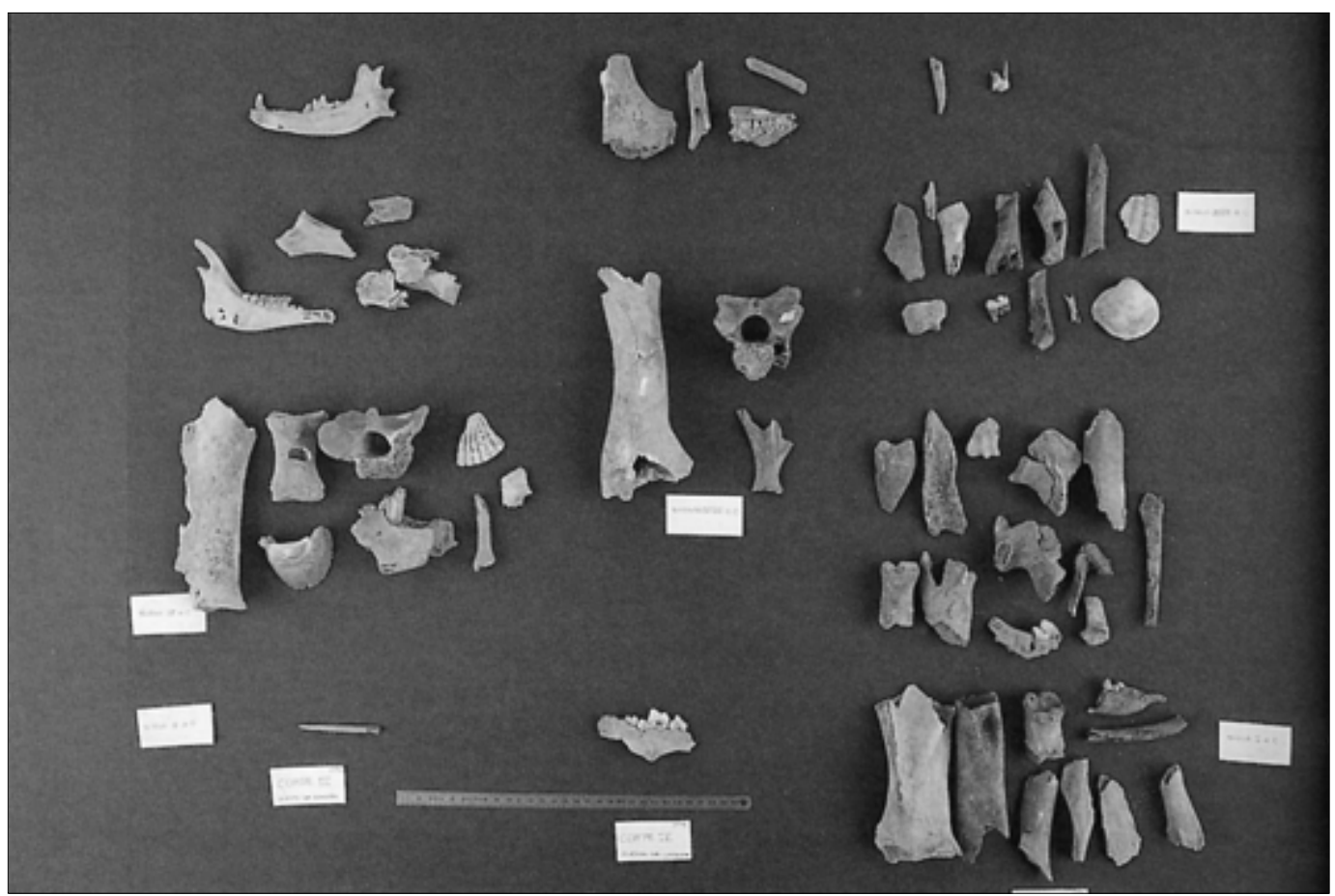

Eloísa Bernáldez Centro de Intervención del IAPH a Ley $16 / 85$, de 25 de Junio, del Patrimonio Histórico Español y la Ley I/91, de 3 de Julio, del Patrimonio Histórico de Andalucía mencionan entre los objetos a proteger los restos paleontológicos de nuestra Península y Comunidad; por lo que huelga justificar en estas líneas el interés que puede tener la sociedad y la Administración en poner en marcha un Servicio de Análisis Paleobiológico, anunciado en el Boletín del Instituto Andaluz del Patrimonio Histórico (Junio, 1996).

Este aceptado interés se ratifica a medida que los resultados cientíícos demuestran la relevancia de la Paleobiología como ciencia de intervención en la conservación de nuestro patrimonio histórico. De ahí que éste sea el momento de incentivar la investigación que tenga por objetivo apoyar con el estudio paleobiológico la protección y restauración del registro fósil; al menos, este nuevo servicio así lo entiende.

Nuestra intervención tendrá dos campos bien definidos. Por una parte tendremos una actuación urgente sobre los hallazgos paleontológicos que no estén co- nectados a la presencia humana, a partir de los cuales interpretamos la historia natural que precedió a la aparición del hombre. Por otro lado, hay una intervención sistemática sobre el material subfósil registrado en los yacimientos arqueológicos ajustados al programa de Arqueología Urbana de la Dirección General de Bienes Culturales.

\section{La intervención paleontológica}

En el caso de los restos estrictamente paleontológicos recopilaremos cuanta información nos llegue con el fin de proporcionar material fósil a los investigadores y una Carta Paleontológica de la que se servirá el gestor encargado de la protección. Parte de esta carta se realizó en 1986 para la Consejería de Cultura (Bernáldez, 1988); en ella incluimos la situación de algunos yacimientos paleontológicos de la provincia de Sevilla y los resultados del análisis paleobiológico como criterio de valoración del sitio. Así calificamos como extraordinario el hallazgo de icnitas de dinosaurios en el Arroyo Trujillo de Cantillana (Sevilla), algo que nos pareció inaudito 
si tenemos en cuenta que durante el Pérmico, período paleozoico en el que fue datado, aún no habían aparecido los dinosaurios. Este hallazgo tiene como consecuencia más inmediata la revisión cronológica de la facies para la que habrá que retrasar su datación, al menos, en unos 60 millones de años.

Igual de importante consideramos los continuos hallazgos del elefante de colmillo recto (Palaeoloxodon antiquus) conservados en las numerosas graveras de las terrazas del Guadalquivir que van desde San José de la Rinconada hasta Brenes. La presencia de molares, cráneos, húmeros o colmillos con $4 \mathrm{~m}$. de longitud avalan la riqueza paleontológica de esta zona que viene siendo mermada por una destrucción diaria, hecho que demuestra la urgencia con la que debe ser vigilada esta zona (Bernáldez y Mazo, 1989).

\section{La intervención arqueozoológica}

La mayor parte de nuestro esfuerzo, sin embargo, está dirigida al estudio de la evolución de las relaciones del hombre con el ecosistema circundante partiendo del estudio arqueozoológico del material orgánico conservado en los yacimientos arqueológicos de nuestra región.

Aunque la mayoría de los investigadores basan sus estudios en la reconstrucción paleoeconómica de los yacimientos, tal como lo contempla la Arqueozoología (Davis, 1989), sin plantearse los cambios naturales y antrópicos que ha podido experimentar el depósito a lo largo del tiempo, consideramos que antes debemos analizar la representatividad del depósito fósil como muestra de la actividad trófica del antiguo poblado.

Esta valoración parte del análisis tafonómico del yacimiento y de la inferencia de los resultados bioestratinómicos obtenidos en ecosistemas naturales de nuestra región. Tanto la Tafonomía, que trata sobre el origen y posterior conservación de depósitos fósiles, como la Bioestratinomía, que estudia la formación de depósitos óseos en ecosistemas naturales, son utilizadas junto a la Etnografía como ciencias básicas para conseguir nuestros objetivos. Con ellas obtenemos unos modelos de depósitos con los que comparar o desde los que inferir los resultados que hasta ahora no existían.

Los métodos tafonómicos de nuestro estudio no responden a los tradicionalmente empleados en los yacimientos, sino que han sido inferidos de los aplicados en el estudio bioestratinómico de la Reserva Biológica de Doñana (Bernáldez, 1996b). De aquí obtuvimos la conclusión de que cualquier depósito fósil debe ser valorado por el contenido fósil expresado en función del volumen excavado, y no sólo por la acumulación de restos o de individuos, y por el porcentaje de esqueleto conservado de cada ejemplar registrado. En cualquier caso, la mejor explicación que podemos dar sobre este nuevo enfoque de la Arqueozoología viene dada por un ejemplo; el yacimiento arqueológico de la Puerta de Córdoba en Carmona nos servirá para exponer los criterios, métodos y técnicas empleados.

\section{ESTUDIO TAFONÓMICO Y PALEOBIOLÓGICO DEL REGISTRO ÓSEO DE LA PUERTA DE CÓRDOBA DE CARMONA}

\section{Introducción}

La mayoría de los estudios arqueozoológicos actuales consideran el material óseo faunístico extraído de los yacimientos arqueológicos como una muestra representativa de la alimentación de antiguos pobladores cuando, en realidad, al desconocer las características tafonómicas del depósito y su interpretación en base a las pautas de formación de depósitos actuales no podemos asegurar que la totalidad de la muestra sean desechos del consumo.

El estudio tafonómico del registro óseo excavado en la Puerta de Córdoba ha sido abordado bajo criterios bioestratinómicos - formación de depósitos óseos actuales- deducidos de estudios realizados en ecosistemas naturales (Bernáldez, 1996a) y antrópicos (Bernáldez, 1996b) que podrían ayudarnos a interpretar el posible origen de la asociación faunística y los acontecimientos pre y postdeposicionales que han podido modificar la información original.

Los criterios bioestratinómicos nos servirán para discriminar, en lo posible, el depósito antrópico del natural; hay que tener en cuenta el papel tan importante que ha podido desempeñar la dinámica de sedimentación y deposición de la ladera a lo largo del tiempo en las condiciones del depósito y de la información estrictamente antrópica original.

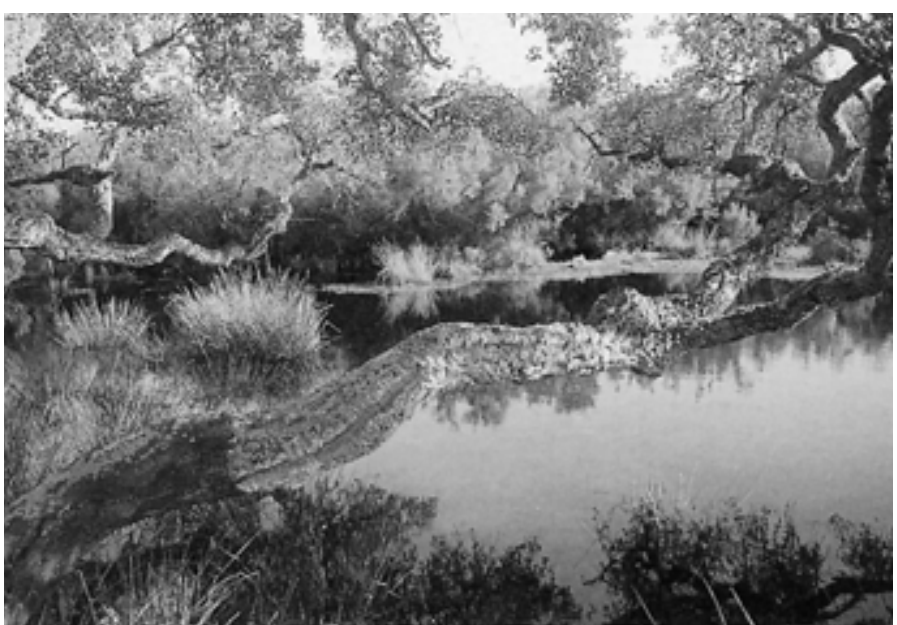

El material óseo corresponde casi en su totalidad a ungulados actualmente domesticados, por ello, el estudio tafonómico del mismo ha seguido las pautas observadas en un estudio bioestratinómico realizado en un matadero de la provincia de Sevilla, es decir, se han inferido las características de formación de un depósito antrópico.

La exposición del análisis tafonómico del yacimiento consta de una cuantificación de la acumulación y estado de conservación de los huesos e individuos ente-
I. Alcornocales de Doñana. En ecosistemas naturales como éste realizamos el seguimiento de los procesos que intervienen en la formación de un depósito de huesos del que inferimos los resultados en la interpretación tafonómica de los depósitos fósiles. 
rrados, un análisis de la distribución espacial de los mismos y una caracterización biológica de los ejemplares. Con estos análisis tratamos de interpretar, con la mayor fiabilidad posible, por un lado, el estado actual de conservación del yacimiento y, una vez determinadas las condiciones tafonómicas, con la información procedente de la actividad humana reconstruimos el tipo de economía que se desarrolló a lo largo del tiempo en función de la pérdida de información biológica.

\section{Criterios tafonómicos y biológicos de valoración del yacimiento}

En la interpretación tafonómica y económica del yacimiento en estudio hemos tenido en cuenta que, aunque la densidad de individuos en cada corte supera al menos en 10 veces más la densidad de cadáveres encontrados en el más rico de los biotopos naturales (Bernáldez, 1996b), demostrando así la intencionalidad del depósito y la intervención del hombre; sólo contamos con 49 huesos de vaca, caballo, cerdo, caprino y perro, básicamente, registrados en 20,43 $\mathrm{m}^{3}$ de tierra. Esta densidad junto con una asociación faunística compuesta por especies actualmente domesticadas define al agente productor del depósito, el hombre. Conocido el origen nos hemos planteado analizar la conservación del depósito y la posible actividad humana que ha generado dicho registro. Por esta razón hemos adoptados estos criterios en la toma y análisis de datos:

Bioestratinómico. Las pautas actuales de formación de los depósitos naturales y antrópicos serán la referencia con la que contemos a la hora de interpretar los resultados tafonómicos y biológicos.

Energético. Las pautas actuales de aprovechamiento de los recursos que utiliza el hombre nos servirán para entender el tipo de depósito registrado, condicionado a las pautas de conservación presente. Así cuando tenemos restos de animales actualmente domesticados con cortes intencionados no existe la menor duda de su conexión con el hombre, pero desconocemos cuál ha sido en concreto la actividad que produjo el depósito y la información que se ha podido perder, datos imprescindibles para reconstruir la evolución de las técnicas usadas en la economía. Para el material óseo procedente de las especies domesticadas hemos recurrido al criterio de aprovechamiento que se usa en los actuales mataderos, en los que hemos observado qué tipo de despojos se genera en cada fase de preparación y distribución de los animales sacrificados hasta su consumo. Dicho criterio es el de beneficio cárnico que explicaremos en el siguiente apartado.

Para el caso de los moluscos, el criterio energético está basado en la densidad y frecuencia de ejemplares con un tamaño óptimo de consumo, que será distinto para cada especie, $y$ en las actuales costumbres, siempre que no coincidan con las características bioestratinómicas de la actual asociación de moluscos de los bancos que se forman en la playa.

Tafonómico. Las deducciones acerca del tipo de economía desarrollada dependen de las condiciones de con- servación del depósito que serán cuantificadas según estos conceptos: densidad de elementos, conservación de los ejemplares y distribución espacial. El estudio comparativo de los sectores de este yacimiento o con otros coetáneos requiere una medida de la acumulación de elementos, sean huesos o individuos, en función del volumen excavado, puesto que ya se ha demostrado en otros trabajos (Bernáldez, 1996b) la variabilidad tan significativa que existe entre número de piezas extraídas de un depósito y el volumen del mismo. Por otro lado, las partes anatómicas conservadas de un animal y las huellas impresas sobre la superficie de los huesos suelen indicar los procesos a los que han estado sometido hasta el presente (Behrensmeyer, 1978).

Morfobiométrico. Las características biológicas de los animales sacrificados es uno de los datos importantes que se necesitan para deducir el tipo de depósito y de economía desarrollada, de la que pretendemos conocer tanto las especies preferentes en el consumo como la edad, el sexo y las condiciones físicas de los animales sacrificados; cualidades que, lógicamente, fluctuarían en función de la riqueza del poblado.

Ecológico. La relevancia de una especie en el conjunto faunístico tiene que ser reflejada en función de la asociación de especies para así entender los recursos naturales del medio físico y el aprovechamiento que de él hizo el hombre. Para la interpretación del yacimiento, desde el punto de vista faunístico, necesitamos conocer la actual comunidad faunística y las costumbres tróficas del hombre de las que tengamos noticias (por información oral y documentada).

\section{Material y métodos}

Se han estudiado 49 huesos y 4 restos de moluscos hallados en 20,43 $\mathrm{m}^{3}$ procedentes de tres cortes excavados y distribuidos por el yacimiento. En total se han identificado cinco especies de mamíferos, un ave de la talla de la perdiz (no se puede determinar porque las epífisis están roídas) y tres de moluscos (dos pelecípodos marinos y un gasterópodo terrestre); de las primeras tenemos que, excepto el perro, son especies actualmente consumidas y usadas como animales de transporte y tracción; y de las segundas observamos que las dos especies marinas forman parte de nuestra actual economía.

Antes de exponer los métodos utilizados para la obtención de los datos tafonómicos y biológicos necesarios para nuestro estudio puntualizaremos sobre la fiabilidad de algunas variables consideradas en la mayoría de los estudios actuales.

\section{Consideraciones generales}

El estudio tafonómico y arqueozoológico del conjunto óseo ha tenido en cuenta estas consideraciones que creo oportuno explicar antes de exponer las variables que han cuantificado las condiciones del depósito:

I. La acumulación de elementos no expresa la riqueza del depósito respecto a otro si no está referida al volu- 
men excavado, es decir, si no es una medida de densidad. De no ser así es incorrecto el estudio comparativo de la acumulación de elementos tanto de las unidades estratigráficas de una misma excavación como entre yacimientos. Aún así, hay que tener en cuenta el volumen de tierra excavado, puesto que la diferencia de tierra removida conlleva una diferencia significativa de huesos; de modo, que a un mayor volumen excavado le corresponde una densidad menor de elementos, aún cuando el número de huesos sea mayor. Igualmente ocurre cuando el estudio comparativo se realiza en función de la frecuencia de restos o de individuos, sólo si ambos depósitos contienen un número significativo de restos puede valorarse la riqueza de elementos (Klein y Cruz-Uribe, 1984), es decir, que e.g. un $80 \%$ de huesos de vacas registrado en un total de 200 huesos no es comparable con otro con 20 elementos y aún menos si el volumen de tierra difiere significativamente entre depósitos.

2. La importancia económica de una especie expresada por el número de individuos (NMI) es una información incompleta, puesto que en los mataderos actuales (Bernáldez, 1996a) hemos comprobado que la ausencia de restos óseos de algunas especies tiene su explicación en el aprovechamiento cárnico que de ellas se hace, e.g. la ausencia de restos de cerdo en los yacimientos no implica necesariamente la ausencia en la dieta si la estructura excavada responde, en general, a una despojería. Por lo tanto, la interpretación económica del depósito dependerá del conocimiento que tengamos sobre el estado de conservación del individuo y del hueso. Este estado se expresa por el porcentaje de esqueleto preservado o indice de conservación esquelética (ICEn) tanto del total como de cada una de las unidades anatómicas conservadas y, además, por las huellas registradas en la superficie del hueso (trazos, talla) que nos indicarán la actividad de la que procede (rituales, despiece, consumo).

3. Si como mencionamos es importante conocer el estado de conservación del individuo, hemos de tener en cuenta que cada especie tiene un número determinado de huesos que aumenta o disminuye su representación en la muestra, e.g. el mismo número de huesos de un caballo y de un perro hallado en un depósito indica que el esqueleto del primero está mejor conservado porque tiene 199 huesos, mientras que el cánido tiene $28 \mathrm{I}$ huesos.

\section{Nunca el número de restos debe usarse como indi-} cador de abundancia de una especie, tanto si el resto es un hueso como una esquirla. En el primer caso ya he mencionado la diferencia de huesos entre los esqueletos de las distintas especies y el efecto que produce sobre la representación de especies en el conjunto y si consideramos los fragmentos, éstos no pueden representar al animal porque desconocemos el número de trozos óseos que puede componer un hueso completo.

\section{Variables bioestratinómicas y tafonómicas}

Las variables bioestratinómicas usadas parten de las observaciones realizadas en el estudio realizado en un ecosistema natural, en Doñana, y en otro antrópico, un matadero de Salteras (Sevilla).

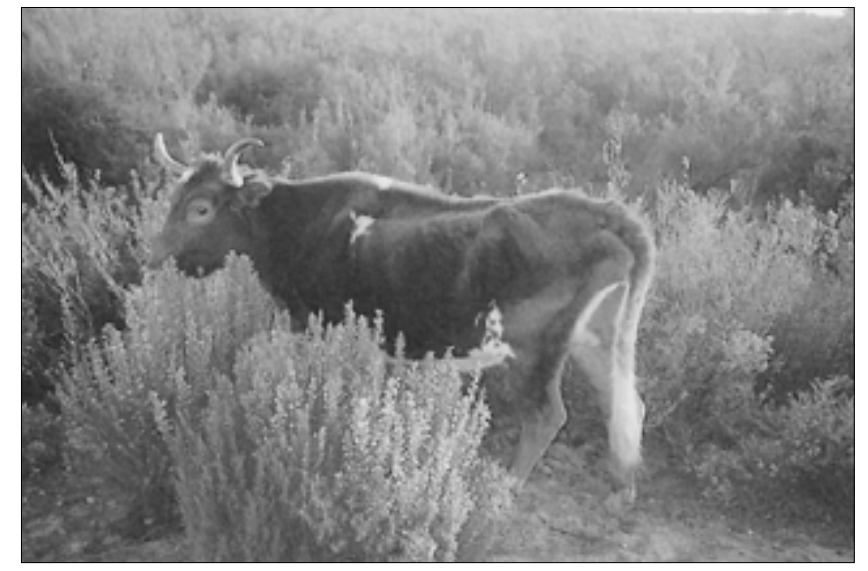

$\varangle$
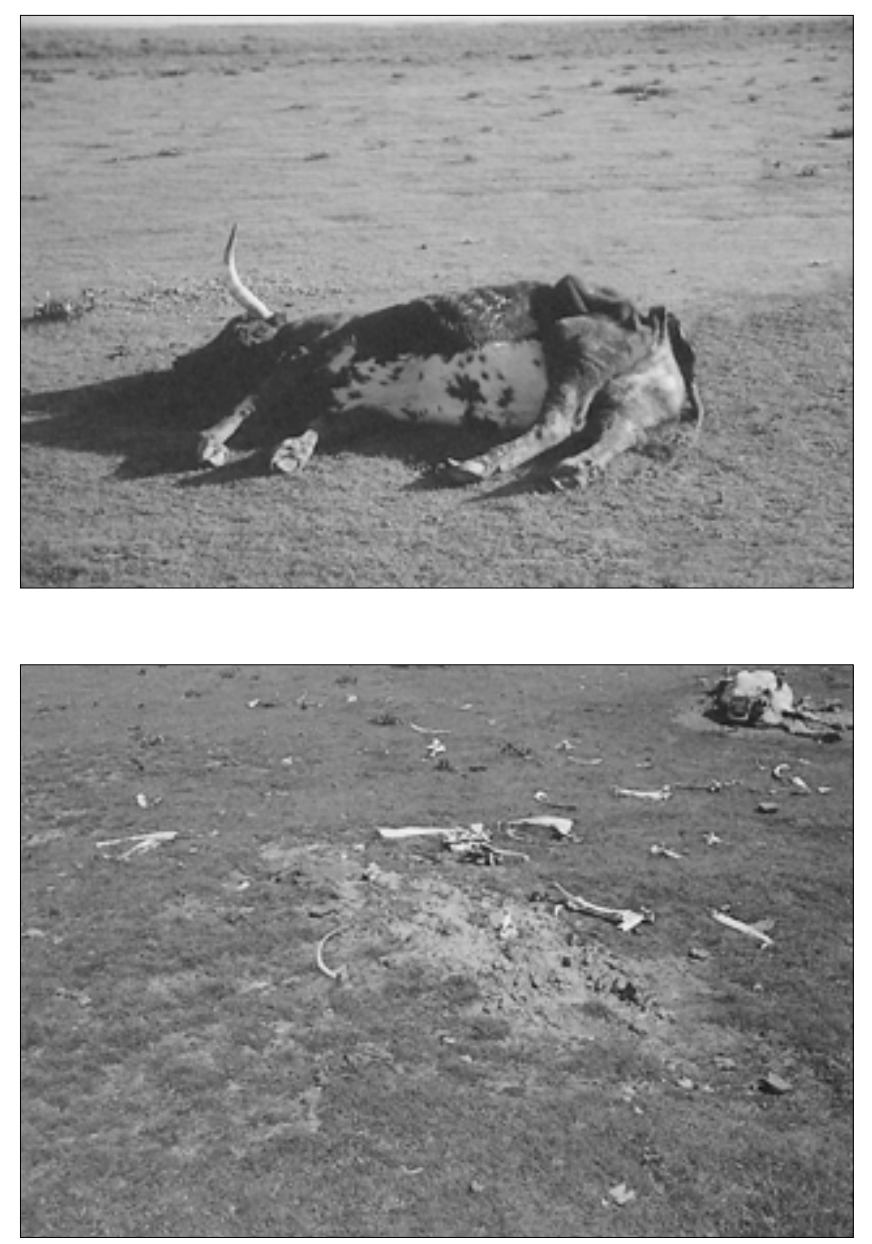

2, 3 y 4. Sucesión de acontecimientos desde la muerte del animal hasta la desaparición del cadáver de la superficie de

Número de huesos -NH-. Todos los elementos han sido identificados y se agruparán como huesos procedentes de la cabeza (NHCAB), del tronco (NHTRO) y de las extremidades distales (NHEXTd).

Número de huesos procedentes de las zonas anatómicas sin beneficio cárnico -NHsbc-. Se considera el total de huesos enteros y fragmentados procedentes de los cortes de las patas, las extremidades distales, y de la cabeza. En el caso en el que encontremos e.g. una epífisis distal y otra proximal cuyas medidas y morfología indiquen que pueden ser del mismo animal y del mismo lado del cuerpo contamos una única pieza.
Doñana. Después de dos años Marisma se conservaba más del $45 \%$ de los huesos, sin embargo, animales con menos de $50 \mathrm{Kg}$ apenas si permanecen un año en este mismo ecosistema. de la muerte de esta vaca en la 
Número de huesos procedentes de las zonas con beneficio cárnico -NHbc-. Esta variable recoge los huesos y fragmentos resultantes del corte en canal del tronco, sobre todo, vértebras y costillas, además de las extremidades proximales.

Contenido fósil -CF-. Mide la densidad de ejemplares por unidad de volumen.

$$
\mathrm{CF}=\mathrm{NMI} / \mathrm{vol} \text {. }
$$

Indice de conservación esquelética -ICEn-. Nos indica el porcentaje de huesos preservado respecto al número de huesos del esqueleto de cada ejemplar estimado. También será calculado para cada unidad anatómica.

$$
\text { ICEn }=\frac{\mathrm{NH}}{\mathrm{NMI} \times \mathrm{NE}} \times 100
$$

donde NE es el número de huesos del esqueleto de los individuos de cada especie, NMI el número mínimo de individuos, $\mathrm{NH}$ el número de huesos registrados.

Número de huesos completos -NHc-. El total de huesos completos junto con la unidad anatómica a la que se refiera es un indicador de la actividad antrópica o natural que ha intervenido en el estado de conservación del hueso. E.g. la presencia de metápodos completos de una vaca o de una cabra nos indica que proceden de la despojería de un matadero, mientras que un fémur completo de estos animales nos induce a pensar en un enterramiento del animal que si fue parte del consumo, al menos, no fue desarticulado con las técnicas habituales.

Número de huesos fragmentados -NHf-. Es un indicador, como la variable anterior, del estado de conservación del hueso y del origen del depósito.

\section{Las características biológicas de los individuos conservados}

A pesar de que más del $80 \%$ de los huesos estudiados son fragmentos, aún hemos podido deducir algunas de las características biológicas de los ejemplares que nos ayudarán a completar la información tafonómica y de la que deduciremos las preferencias tróficas de los pobladores:

La edad estimada por el grado de fusión de las epíísis y diáfisis de los huesos según Noddle (1974), por la erupción de los dientes y por el desgaste dentario según Schmid (1972) y Silver (1980).

El sexo deducido del dimorfismo sexual de cada especie en cuanto a la presencia de cuernas en machos y las diferencias biométricas y morfológicas de los cuernos en ambos sexos.

El tamaño de los ejemplares ha sido medido según von der Driesch (1976). En la interpretación del tamaño hemos tenido en cuenta que según Sánchez-Belda (1987) en nuestra Península existen 27 razas de vacas, 38 de ovejas y 7 de cabras consideradas como autóctonas.

El número mínimo de individuos NMI. Para calcular el número de ejemplares conservados se ha recurrido al contaje de un mismo hueso del mismo lado del cuerpo con tamaño o edad o sexo distintos.

Cada corte, unidad y fase del yacimiento será definido por la acumulación y estado de conservación de las entidades enterradas descritos bajo estos apartados:

a. Composición y estructura de la asociación ósea y malacológica. Se identificarán las especies, el número de huesos, el número de individuos, la edad, el tamaño del animal, el sexo, el manejo antrópico (diferencias de talla relacionadas con la domesticación) y los casos de malformación ósea. Igualmente se identificarán las especies malacológicas, frecuencia, densidad de especies e individuos y el tamaño de los mismos, indicándose la presencia de valvas izquierdas y derechas.

b. Estado de conservación de los ejemplares expresado por el porcentaje de huesos conservados del total del esqueleto, de cada parte anatómica, es decir, de la cabeza, del tronco y de las extremidades distales; y de cada unidad anatómica, cráneo, mandibulas, cuernos, costillas, vértebras, esternón, extremidades proximales (fémur, tibia, fibula, patella, húmero, radio, ulna, escápula y pelvis), extremidades distales metapodiales (metacarpos y metatarsos) y extremidades distales podiales (falanges, calcáneos, astrágalos, tarsos, carpos, sesamoideos, metápodos vestigiales). El tipo de depósito será definido por la frecuencia de huesos procedentes de los cortes del despiece en las zonas sin beneficio cárnico que son las extremidades distales que deberemos hallar completas y de la cabeza que hallaremos fragmentados debido a los cortes de carnicería (cráneo, cuernos cortados por la base, vértebras cervicales) frente a la de los huesos fragmentados procedentes del tronco, la de mayor aportación cárnica, costillas, vértebras, esternón y extremidades proximales, que denominaremos zonas con beneficio cárnico.

El estado de conservación de los huesos se referirá, también, a las condiciones de la superficie en cuanto a la presencia de grietas, mordeduras de carnívoros, huellas de líquenes y concreciones que serán los principales rastros observados. También mediremos el tamaño de los fragmentos con el objetivo de reconocer si hay una selección de los mismos que pudiera identificarnos el transporte del agua por la ladera en el enterramiento de los elementos.

A esta descripción sigue un análisis de la distribución espacial de los huesos con el fín de hallar unas pautas de disposición de los elementos que nos identifiquen los agentes productores y enterradores de los depósitos.

En cuanto al material malacológico, las variables medidas han sido:

Número de elementos -Ne-. Es un contaje de valvas derechas o izquierdas, caracoles o cualquier otra pieza del exoesqueleto de los moluscos identificados,

Número mínimo de individuos -NMI-. Para los gasterópodos se cuenta un individuo por cada concha de 
caracol. En cuanto a los pelecípodos, el método consiste en tomar como número de individuos el número de valvas de un mismo lado de dimensiones similares a las del lado contrario.

Las medidas tomadas han sido la altura de la concha que mide la longitud desde el ápice hasta el borde inferior para los pelecípodos y la anchura máxima de la concha de los caracoles según Lindner (1983).

En el estudio malacológico seguiremos los mismos criterios usados para el análisis de la asociación ósea, exceptuando el bioestratinómico del que sólo tenemos algunas observaciones realizadas en la misma costa de Huelva, en Isla Cristina. Consideraremos la existencia de un conchero, entendiéndolo como despojos del consumo antrópico, aquellas asociaciones de moluscos que presenten estas características:

- En asociaciones con más de 20 ejemplares, más del 50 \% de ellos corresponderán a especies actualmente usadas en nuestro consumo.

- El tamaño de estos ejemplares ha de ser rentable para el consumo, es decir, han de ser adultos en su mayoría.

- Las huellas que demuestren la necesidad del uso de un instrumento nos servirán para determinar al hombre como agente productor.

- La presencia de valvas de ambos lados del animal nos indicarán un posible enterramiento inmediato que reforzará junto con las condiciones anteriores la interpretación del depósito.

En el caso de que alguna especie no presente una estructura de edad homogénea, según el tamaño, (la proporción de adultos no es superior al $50 \%$ ), y, a su vez, observemos huellas de uso antrópico consideraremos que esa especie no ha sido recolectada por su valor dietético, sino que su uso ha sido otro distinto. Para lo que recurriremos a otras fuentes que puedan explicar su presencia.

\section{El aprovechamiento energético actual del ganado en los mataderos de Sevilla}

En el Matadero del Sur de Salteras (Sevilla) cada martes y jueves se sacrifican ovejas, cabras, vacas y cerdos (estos dos últimos de la raza retinta, una de nuestras razas autóctonas) siguiendo un criterio energético que determina las técnicas de descuartizamiento. de modo que los primeros cortes dados en el cadáver van dirigidos a deshacerse de las zonas con un bajo beneficio cárnico, variando en cada especie, y en segundo lugar para preparar el "tronco" (incluye tronco y extremidades proximales), la zona con más $\mathrm{Kg}$ de carne por cada $\mathrm{Kg}$ de huesos.

Estos son los principales cortes observados de donde se obtienen los despojos óseos de un matadero:

a. Corte entre extremidades proximales y metápodos. Así separan las extremidades distales, desde los metápodos hasta las falanges, del resto del cuerpo. Es un corte practicado en vacas, cabras y ovejas que genera huesos metapodiales y podiales completos sin cortes.

b. Corte entre los metápodos y las falanges. Las extremidades distales del corte anterior pasan a la despojería donde separan las falanges para consumo (materia prima del menudo) de los metápodos que serán triturados para piensos. Este corte también se realiza en los cerdos, pero del despiece apenas se generan despojos.

c. Corte de la cabeza. Es el corte que mayor variación presenta entre los cuatro ungulados domesticados que se sacrifican en los mataderos de ganado, siempre en función del beneficio cárnico y de los usos alimenticios. En las vacas suelen separar la cabeza con un corte en el cuello, entre el cóndilo occipital y la primera vértebra cervical; en ovejas y cabras, cortan los cuernos por la base y, no siempre, la cabeza es separada del cuerpo con un corte entre las vértebras cervicales; también es opcional que separen la cabeza de los cerdos del resto del cuerpo. Los despojos generados suelen ser fragmentos del cráneo y de las mandíbulas, algunos dientes y ambos cuernos completos de cada individuo con corte en sus bases.

d. Corte en canal. El tronco del animal es abierto y descuartizado según la demanda de las carnicerías, los despojos óseos producidos suelen ser todos fragmentos con menos de $20 \mathrm{~cm}$ de longitud y con una determinada orientación de los cortes, e.g., las vértebras presentan dos cortes básicos, uno vertical en el cuerpo vertebral y otro a nivel de las apófisis laterales y de la espina neural.

Hemos calculado el beneficio cárnico de cada parte anatómica considerada en el matadero para una vaca, una cabra y un cerdo: cabeza, "tronco" y extremidades distales, es decir, la masa de carne que acompaña a cada Kg de huesos de estas partes; y el estado de conservación (ICEn) de las unidades anatómicas siguientes: cráneo, cuernos, mandíbulas, costillas, vértebras, esternón, extremidades proximales, extremidades distales metapodiales y distales podiales. Con estos datos pretendemos mostrar las tendencias de acumulación y conservación de los esqueletos de cada especie sacrificada en un matadero.

\section{El beneficio cárnico de una vaca retinta}

Para explicar este apartado hemos elegido una vaca de la raza retinta por ser una de las razas autóctonas del SO. de Andalucía con mayor parecido a las halladas en yacimientos contemporáneos al estudiado. En la actualidad estas vacas suelen ser sacrificadas a los tres años teniendo un peso corporal de $410 \mathrm{Kg}$ y un peso esquelético de $47 \mathrm{Kg}$ un esqueleto compuesto por 201 huesos.

La cabeza está compuesta por 20 huesos que componen el $10 \%$ de los huesos del esqueleto, de ellos dos son los cuernos, dos las mandíbulas y el resto es el 


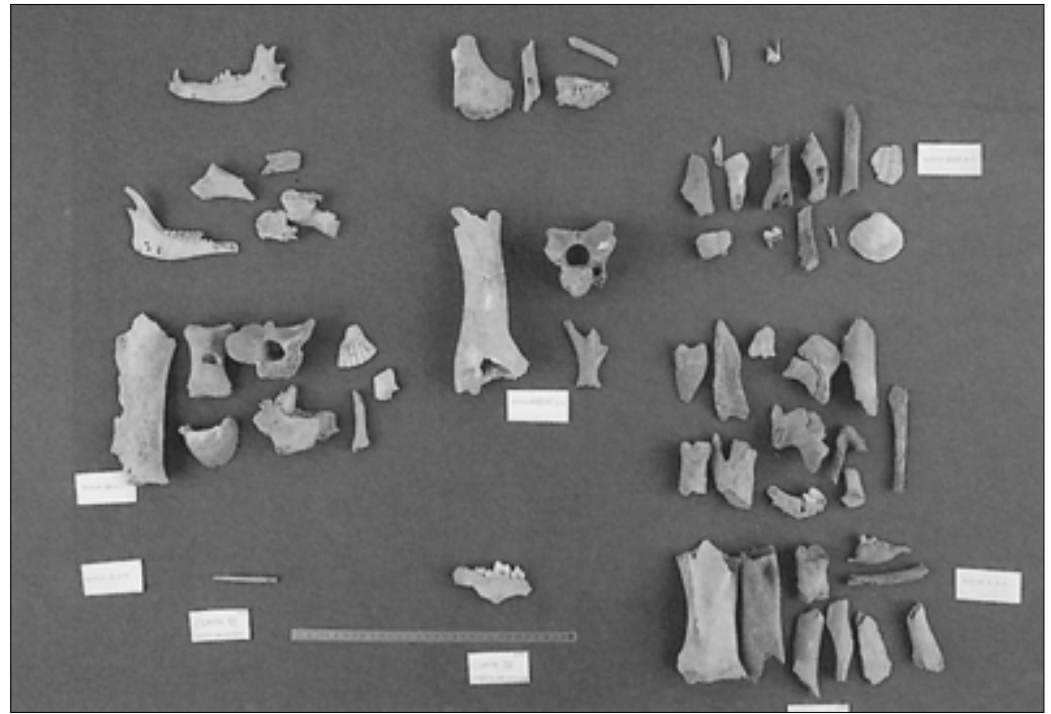

5. Conjunto óseo encontrado en distintos cortes y niveles excavados en la Puerta de Córdoba de Carmona (Sevilla). Restos del consumo humano se entremezclan con otros procedentes de otras actividades del hombre, enterramientos de perros e industria ósea.

6. mandibulas de dos perros de distinta talla. Usualmente los perros encontrados encontrados en yacimientos holocénicos del SO de Andalucía suelen ser del tamaño al que le corresponde a la mandibula situada en la parte inferior; la otra es de un cánido de tamaño similar al de un mastín.

7. Muestra de la actividad industrial entorno al hueso durante el período romano. Fragmento de aguja o pincho de un pasador para el pelo
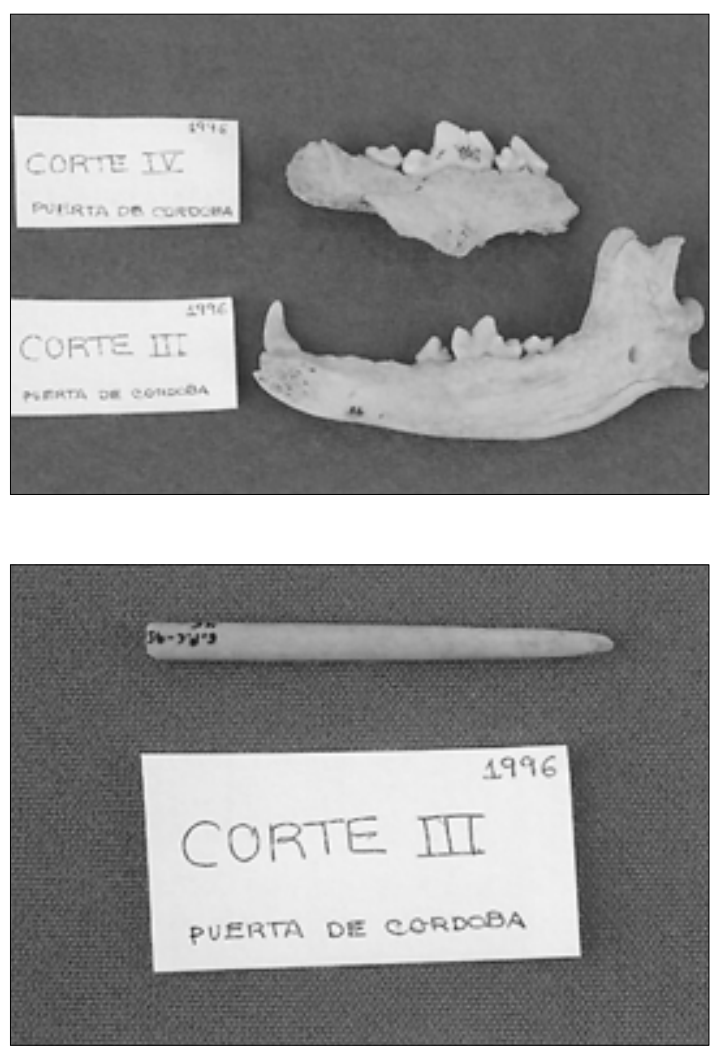

cráneo donde todos los huesos están fusionados. El peso de esta pieza es de unos $16 \mathrm{Kg}$ de los que $14 \mathrm{Kg}$ son de huesos y $2 \mathrm{Kg}$ de partes blandas (cerebro, lengua, laringe, etc.); de manera que el beneficio cárnico es de $0,14 \mathrm{Kg}$ de carne por $\mathrm{Kg}$ de huesos.

El tronco de este animal tiene 26 costillas, 7 piezas del esternón y 51 vértebras a los que hay que añadir los 21 huesos de las extremidades proximales que suponen 103 en total y el 51,2\% del esqueleto; el peso del tronco es de $381 \mathrm{Kg}$ aportados por los $29 \mathrm{Kg}$ de esqueleto y el resto se divide entre los $200 \mathrm{Kg}$ de vísceras y los $151 \mathrm{Kg}$ de masa muscular, incluída la piel. De modo, que el beneficio cárnico del tronco es de casi $12 \mathrm{Kg}$ de carne por Kg de huesos, bastante más alto que el aportado por la cabeza.
Las extremidades distales son 78 huesos que aportan el 38,8 \% de los huesos del esqueleto y pesan 13,5 Kg Entre ellos diferenciamos los cuatro metápodos (dos metacarpos y dos metatarsos, el $2 \%$ de los huesos del animal) que en hueso pesan $1,5 \mathrm{Kg}$, del resto que son dos metatarsos y dos metacarpos vestigiales, dos calcáneos, dos astrágalos, 24 falanges, 12 carpos, seis tarsos y 24 sesamoideos que pesan dos Kg; los $10 \mathrm{Kg}$ restantes están compuestos por la piel, los tendones y las pezuñas, que serán utilizados como materia prima de botones, peines y otros adornos, pero que no reportan beneficio cárnico.

Los huesos que restan en la despojería para ser molidos proceden del corte de las extremidades, cuyos despojos son todos los metápodos enteros; del corte de la cabeza, del que se podría obtener algún fragmento del cuerno, del cráneo y de la mandíbula (algún diente suelto, en ocasiones) resultado de la extracción de la lengua y de los sesos; además, del corte en el cuello, del que encontramos algunos fragmentos de vértebra cervical y del cóndilo occipital; y del corte en canal, de éste podemos tener algunos fragmentos con longitud inferior a $20 \mathrm{~cm}$ procedentes de las costillas y algunas vértebras seccionadas verticalmente.

Así que la despojería está caracterizada básicamente por la presencia de todos los metápodos y, ocasionalmente, por algunos de los huesos mencionados. Un posible depósito óseo de despojos de la matanza de vacas estaría compuesto, por lo tanto, por huesos completos de las extremidades distales metapodiales, metacarpos y metatarsos; y por escasos fragmentos procedentes de la cabeza, de las extremidades distales podiales, es decir, por huesos de las zonas sin beneficio cárnico, éstos suelen ser fragmentos, con menos de $20 \mathrm{~cm}$, de las costillas y de las vértebras. Entre el $95 \%$ y el $98 \%$ de los huesos del esqueleto va adherido a la carne que se distribuirá a las carnicerías y gandinguerías y ese porcentaje pertenece al tronco: el costillar, la columna vertebral y las grandes extremidades proximales. En la Fig. I hemos expuesto los huesos que componen el mayor porcentaje de despojos en un matadero.

\section{El beneficio cárnico de una cabra}

Una cabra adulta de la raza murciana-malagueña (las que sacrifican en Salteras) tiene unos $30 \mathrm{Kg}$ de peso corporal y 205 huesos que pesan $4 \mathrm{Kg}$ repartidos así: 20 huesos de la cabeza procedentes de los dos cuernos, las dos mandíbulas y 16 piezas óseas fusionadas del cráneo que suponen casi el $10 \%$ del esqueleto con un peso de $1,5 \mathrm{Kg}$ que respecto al $\mathrm{Kg}$ de carne que compone la parte blanda de la cabeza viene a determinar un beneficio cárnico de $0,88 \mathrm{Kg}$ de carne por $\mathrm{Kg}$ de huesos.

El tronco con 105 huesos procedentes de 26 costillas, 55 vértebras y siete del esternón, además de los 21 de las extremidades proximales (dos escápulas, dos húmeros, dos radios, dos ulnas, dos fémures, dos tibias, dos fíbulas, dos patelas...), suponen el $51 \%$ del esqueleto y pesan $27 \mathrm{Kg}$ : dos de huesos y $25 \mathrm{Kg}$ de 
carne (ocho $\mathrm{Kg}$ de vísceras y $17 \mathrm{Kg}$ de masa muscular) que reportan un beneficio cárnico de $13,3 \mathrm{Kg}$ de carne por $\mathrm{Kg}$ de huesos.

Las extremidades distales se componen de cuatro metápodos con $350 \mathrm{~g}$ y 76 huesos más con $150 \mathrm{~g}$ que no reportan beneficio cárnico, más que piel, pezuñas y tendones sin aporte cárnico; entre ellos están 12 carpos, seis tarsos, 24 falanges y 24 sesamoideos.

En el depósito de huesos generado por el descuartizamiento de este animal nos encontramos los cuatro metápodos enteros, como en las vacas, y los cuernos cortados por la base, a diferencia de las vacas puesto que la cabeza de cabra se consume completa (excluídos los cuernos). En ocasiones, se separa la cabeza con un corte entre las vértebras cervicales y se fragmenta el cráneo para extraer la lengua y los sesos, de donde se generan algunos despojos óseos procedentes de las mandíbulas y del cráneo (a veces hay dientes sueltos). Este mismo proceso es practicado en ovejas y carneros.

Del matadero sale el $97 \%$ de los huesos adheridos a la carne que se venderá a carnicerías y gandinguerías procedentes del tronco y, frecuentemente, de la cabeza completa. En la Fig. 2 tenemos una representación gráfica del despiece de este animal y los despojos óseos que suelen quedar en el matadero.

\section{El beneficio cárnico en el cerdo retinto}

Las técnicas de despiece aplicadas en el cerdo apenas generan despojos óseos en el matadero porque hasta la piel es consumida y sólo en algunas ocasiones se le corta la cabeza, pudiendo quedar en el matadero alguna vértebra cervical producto del corte y alguna falange del corte de los dedos. Aún así exponemos los mismo datos medidos en las especies anteriores.

Los 269 huesos del esqueleto se reparten entre los 18 huesos de la cabeza aportados por las mandíbulas y el cráneo que componen el 6,7 \% del total y pesan $3,5 \mathrm{Kg}$ procedentes de $2,5 \mathrm{Kg}$ de huesos y uno de carne, es decir, que el beneficio cárnico es de $0,7 \mathrm{Kg}$ de carne por $\mathrm{Kg}$ de hueso. El tronco, que se considera practicamente todo excepto la cabeza, aporta un beneficio de $14,8 \mathrm{Kg}$ de carne por cada uno de huesos, y en él se incluye el animal sin cabeza; $7,5 \mathrm{Kg}$ corresponden al esqueleto y $99 \mathrm{Kg}$ a la carne, de los que $34 \mathrm{Kg}$ son de las vísceras y $65 \mathrm{Kg}$ a la masa muscular.

Del total de huesos del tronco tenemos que cuando cortan estos animales por los dedos, estos contienen I 60 huesos, casi el $60 \%$ del total. El tronco tal como lo entendemos en vacas y cabras está compuesto por 30 costillas, 56 vértebras, seis piezas del esternón, 31 huesos de las extremidades proximales, 16 metápodos, 10 tarsos, 16 carpos, dos astrágalos, dos calcáneos, 64 falanges y 48 sesamoideos que hacen un total de 126 huesos de las extremidades distales podiales. En la Fig. 3 se exponen los cortes y despojos óseos que suelen quedar en las despojerías de los mataderos.
Fig. I

Cortes del despiece de una vaca y despojos óseos en el matadero actual

Esqueleto de una vaca donde se indican los cortes del despiece y los huesos que quedan en la despojería del matadero de Salteras (Sevilla) marcados en negro
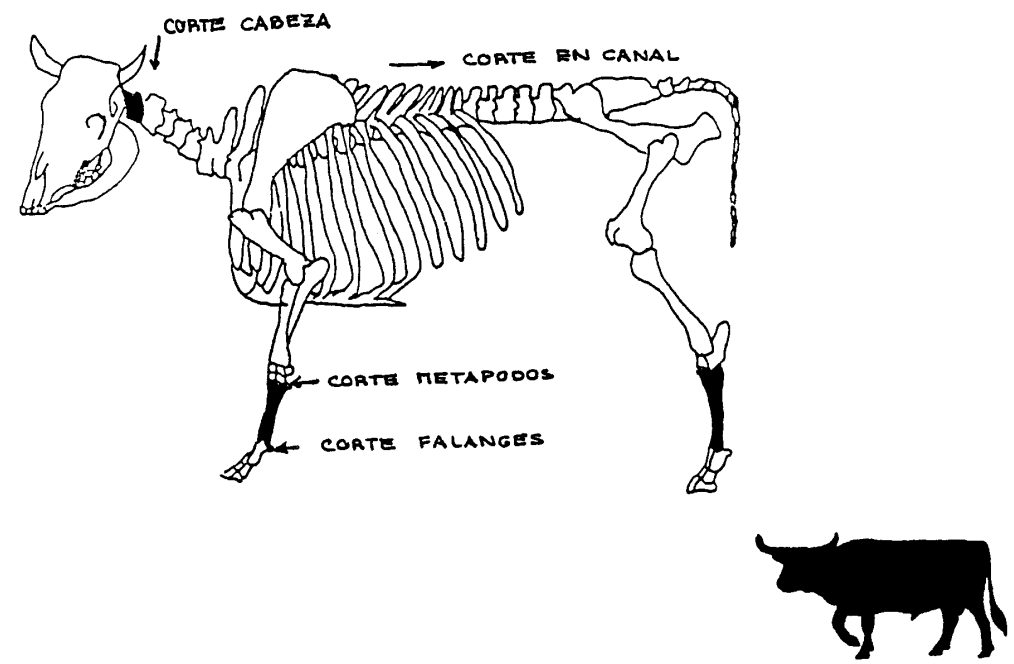

Fig. 2

Cortes del despiece de una cabra y despojos óseos en el matadero actual

Esqueleto de una cabra en el que se indican los cortes del despiece y los huesos que suelen quedar en la despojería del matadero de Salteras (Sevilla) marcados en negro

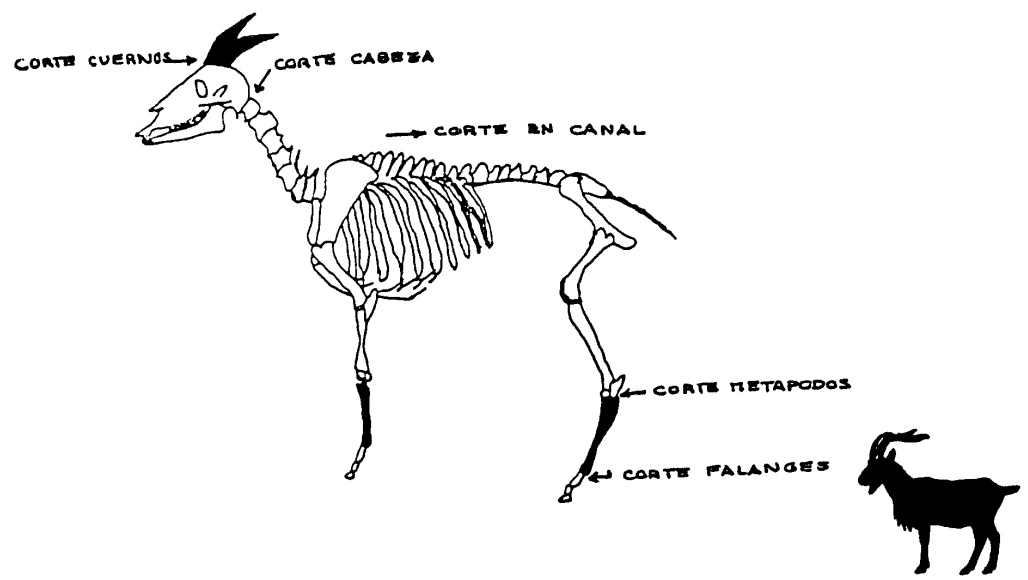

Fig 3

Cortes del despiece de un cerdo y despojos óseos en el matadero actual

Esqueleto de un cerdo donde se marcan los cortes del despiece y los huesos que suelen quedar en la despojería del matadero de Salteras (Sevilla) marcados en negro

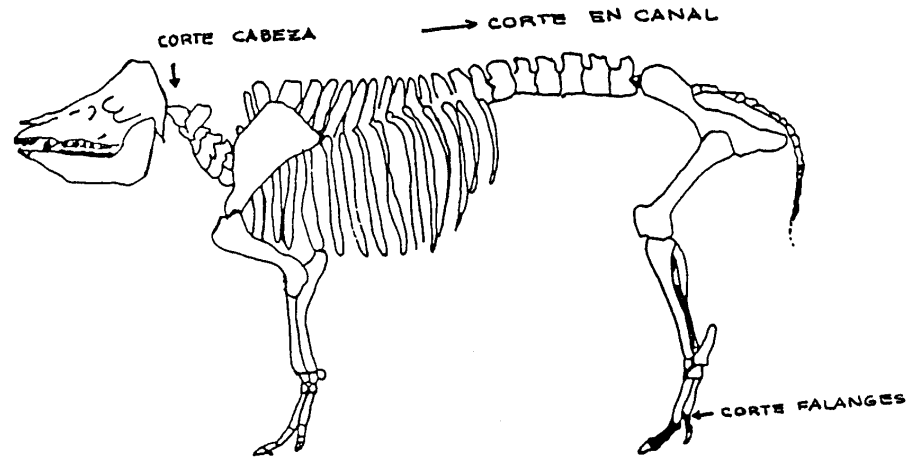




\section{La despojería del matadero de ganado}

El conjunto óseo producto del despiece del ganado que queda en una despojería está compuesto en más de un $90 \%$ del total por los huesos de las zonas sin beneficio cárnico o con un bajo valor cárni$\mathrm{co}$, es decir, de las extremidades distales y de la cabeza, y en una mínima representación podemos encontrar algunos fragmentos de huesos del tronco producto de los cortes en canal y del cuello. Exactamente, en un matadero esperamos hallar todos los metápodos enteros de vacas, cabras y ovejas y los cuernos cortados por la base de estas últimas; lo que suponen un $2 \%$ de los huesos del esqueleto de vacas y ovejas y el $3 \%$ de los de cabras y carneros.

Consideraremos que un depósito óseo hallado en yacimientos arqueológicos es una despojería si cumple estas condiciones:

I. Encontraremos restos de especies que actualmente son sacrificadas en los mataderos.

2. Los fragmentos óseos son todos, o más del $90 \%$, identificables y presentan cortes de instrumentos en la superficie, siendo el porcentaje de restos indeterminados nulo o inferior al $10 \%$.

3. La conservación del individuo se corresponde con las tendencias descritas para cada especie, de modo, que la mayor parte de los huesos conservados, completos o fragmentados, proceda de las zonas anatómicas sin beneficio cárnico y en escaso número del tronco cuando corresponda al corte en el cuello (vértebras cervicales) o al corte en canal (vértebras y costillas).

4. La proporción de huesos de ambos lados del animal y la de cuernos respecto a la de metápodos nos indicarán el estado de conservación del depósito desde su formación. De modo que cuanto más se asemeje a las proporciones esperadas para una despojería actual (cuatro metápodos por cada dos cuernos en cabras y carneros) mayor fiabilidad tendremos a la hora de interpretar económicamente el depósito óseo.

5. Si las características biológicas de los ejemplares registrados muestran unas tendencias determinadas en cuanto a la estructura de edad, sexo y raza como observamos en el matadero de Salteras, el depósito óseo estará mostrando unas costumbres tróficas del hombre del siglo XV (Bernáldez, 1996a), hasta que hallemos otros yacimientos más antiguos con estas mismas características.

Hay que tener en cuenta que en la actualidad los huesos no son enterrados sino molidos y que no generan un depósito subterráneo, además hay que considerar que los depósitos de los yacimientos arqueológicos situados en actuales ciudades suelen estar sometidos a la dinámica urbana desde hace siglos y que ello conlleva hasta la pérdida total del depósito.

\section{El origen del depósito faunístico de la Puerta de Córdoba}

Ya hemos mencionado que la relativa alta densidad de individuos y la única presencia de especies domesticadas en el registro implica al hombre como único agente productor del depósito. La actividad que ha podido generar este acúmulo de desechos es el objetivo de nuestro estudio, así como la posible intervención del mismo en la remodelación de los depósitos originales debido a las labores de construcción realizadas a lo largo del tiempo en este lugar.

La presentación de los resultados se hará por cada corte, unidad estratigráfica y fase de deposición, de esta manera se facilita la labor de unir o descartar unidades de las distintas estructuras arqueológicas.

\section{Corte III. Siglo I d.C.- presente}

Dentro de este corte de 2,7 $\mathrm{m}^{2}$ de superficie por dos $\mathrm{m}$ de potencia se hallaron cuatro niveles con restos faunísticos; los 1,62 $\mathrm{m}^{3}$ de volumen suponen el $30 \%$ del total excavado y un contenido fósil de I, I indivi$\mathrm{duo} / \mathrm{m}^{3}$. El total de huesos registrados ha sido de 12 con un peso de $463,5 \mathrm{~g}$ y seis ejemplares como mínimo correspondientes a vacas con menos de cuatro años que, por su tamaño y madurez, bien puede ser una hembra; un caballo adulto de estatura similar a los actuales caballos medidos en Doñana; cerdos con unos dos años y medio, un caprino con un año y perros de mediana estatura y adultos. Son especies de consumo y uso humano de los que no hemos encontrado ni el $5 \%$ de sus esqueletos.

En función de la posición de los niveles con fauna dentro de la estratigrafía observada hemos definido tres fases en este corte:

Fase I. Determinada por el nivel I 84 datado en el I d.C. y en cuyo volumen, $0,324 \mathrm{~m}^{3}$, se rescató un fragmento de hueso pulido a modo de aguja, para sujetar el pelo, que pesó $40 \mathrm{~g}$ procedente de una extremidad larga de un ungulado de mediano a gran tamaño (cerdo o vaca). El contenido fósil es de $3, I$ individuos $/ \mathrm{m}^{3}$, superior al del corte.

Fase II. A ésta corresponde el nivel I 52 datado con posterioridad al siglo IV d.C. en cuyos $0,324 \mathrm{~m}^{3}$ identificamos un fragmento de vértebra cervical con $73 \mathrm{~g}$ sin fusión del disco y otro de mandíbula con presencia del tercer molar con $84 \mathrm{~g}$ de una vaca con menos de cuatro años y de pequeña talla, posiblemente, una hembra según hemos podido contrastar con las medidas que tenemos de las actuales vacas marismeñas; una falange $\mathrm{I}$, otra tercera y una escápula rota recientemente de un caballo adulto y de talla similar a los caballos de Doñana que pesaron 65, 30 y $100 \mathrm{~g}$ respectivamente; un fragmento de ulna con 3,5 g sin fusión de la epífisis de un cerdo con unos dos años y medio (dudas de su intrusión en el depósito por el aspecto poco mineralizado del hueso); y un fragmento de tibia de un perro adulto con $8 \mathrm{~g}$ en la que apreciamos el corte de carnicería como indicador de su consumo. 
En resumen, hay cuatro especies domesticadas representadas por menos del $5 \%$ del total de huesos del esqueleto y del peso del mismo, de donde deducimos que la vaca y el cerdo fueron consumidos, los huesos conservados son parte de la zona de beneficio cárnico y están fragmentados por un instrumento; mientras que los restos del caballo no presentan corte alguno, tanto los de las zonas sin beneficio cárnico como los del resto del cuerpo, lo que indica que fue enterrado inmediatamente después de muerto sin formar parte del consumo; un hecho que no ocurrió con el perro que por el criterio energético considerado en el presente trabajo tenemos que fue descuartizado, lógicamente, para ser comido. El contenido fósil de esta fase es de 12,3 individuos $/ \mathrm{m}^{3}$ representados por siete huesos que pesaron $363,5 \mathrm{~g}$.

Fase III. En los niveles 144 y | 42 , con $0,972 \mathrm{~m}^{3}$, hemos identificado un fragmento de costilla y otro de pelvis de un pequeño animal con 4,5 y $16 \mathrm{~g}$ cada uno y con cortes de carnicería; un fragmento con cortes de occipital de un cerdo que por la falta de cierre de las suturas deducimos que era un animal con menos de dos años y medio, el fragmento pesó $6,5 \mathrm{~g}$; de un caprino con menos de un año encontramos un trozo de mandíbula derecha con el primer molar decidual y saliendo el primer molar de adulto, pesa $33 \mathrm{~g}$; y una mandíbula derecha de un perro que pesó $40 \mathrm{~g}$ de la misma talla que el de la fase anterior. Junto con estos restos óseos hallamos un fragmento de concha peregrina (Pecten sp.).

En total encontramos cinco huesos que pesaron $100 \mathrm{~g}$ correspondientes a tres mamíferos que forman parte de la dieta actual, cuyos cortes de carnicería nos indican su origen antrópico, así como la baja representación del esqueleto, menos del $5 \%$ del total de huesos y del peso esquelético, nos indica que son desechos del consumo y no de un matadero o de una carnicería. Tanto el cerdo como el caprino fueron sacrificados antes de ser adultos como viene siendo costumbre en el consumo actual, el perro pudo ser enterrado completo sin que hubiese formado parte de la dieta. El contenido fósil es de 4,I ejemplares $/ \mathrm{m}^{3}$.

\begin{tabular}{lllllll}
\hline C-III & NH & PH g. & NMI & ICEn & NHC & NHf \\
\hline BOS & 4 & 177,5 & 1 & 2 & 0 & 4 \\
\hline EQUUS & 3 & 195 & 1 & 1,5 & 3 & 0 \\
\hline SUS & 2 & 10 & 1 & 0,4 & 0 & 2 \\
\hline CAP & 1 & 33 & 1 & 0,5 & 1 & 0 \\
\hline CAN & 2 & 48 & 2 & 0,4 & 1 & 1 \\
\hline T. & 12 & 463,5 & 6 & & 5 & 7 \\
\hline
\end{tabular}

Tabla I

Número de huesos, peso de los mismos, número mínimo de individuos, porcentaje de huesos conservados, número de huesos completos y número de huesos fragmentados por instrumento. Bos -vaca-, Equus -caballo-, Sus -cerdo-, Cap -caprino-, Can -perro-. Corte III de la Puerta de Córdoba de Carmona.

\section{Corte IV. I d.C.-presente}

En un corte de $4,83 \mathrm{~m}^{3}$ de volumen se estimó que el 18,8\% del mismo contenía restos faunísticos distribuídos en tres niveles discontínuos. Los ocho huesos identificados pesaron 469,5g correspondientes a cuatro ejemplares de otras cuatro especies de mamíferos actualmente domesticados, tres de actual consumo, vacas, cerdos y caprinos, y un perro. Los tres niveles componen tres fases que sumaron $0,91 \mathrm{~m}^{3}$ de volumen y mostraron un contenido fósil de 0,82 individuos $/ \mathrm{m}^{3}$, inferior al corte anterior, de los que se conservaron menos del $5 \%$ de los huesos y del peso del esqueleto.

Fase I. En el nivel 297 hallamos una mandíbula de un perro de gran talla que mantenía aún la muela carnicera, por las dimensiones parecía corresponder a un lobo, pero la forma nos hace pensar en un gran perro como el mastín, este resto pesó $20 \mathrm{~g}$ En un volumen de $0,132 \mathrm{~m}^{3}$, el contenido fósil fue de 7,6 individuos $/ \mathrm{m}^{3}$.

Fase II. El nivel 288 contenía un fragmento de vértebra cervical con $98 \mathrm{~g}$ y con cortes producidos por el despiece, el corte del cuello, con cierta deformación y un húmero fragmentado con $248 \mathrm{~g}$ de una vaca con menos de cuatro años por la ausencia de fusión del disco vertebral; y un fragmento de escápula roída con $13 \mathrm{~g}$ de un cerdo. En total encontramos tres huesos con $359 \mathrm{~g}$ de dos individuos domesticados en $0,31 \mathrm{~m}^{3}$, lo que nos proporciona un contenido fósil de 6,5, cuyos restos son desechos de consumo según las zonas del cuerpo halladas que fueron inmediatamente enterrados según deducimos del aspecto de la superficie ósea. Tanto la vaca como el cerdo son de tamaño pequeño, aún cuando son subadultos.

Fase III. En un volumen de $0,468 \mathrm{~m}^{3}$ que compone el nivel 222 registramos cuatro huesos con $90,5 \mathrm{~g}$ de tres ungulados domesticados de actual consumo que proporciona un contenido fósil de 6,4 individuos $/ \mathrm{m}^{3}$. Hallamos un fragmento de pelvis de una vaca pequeña con manchas propias de las zonas estancadas con gran cantidad de materia orgánica similar a los pozos ciegos y alcantarillados; un fragmento de maxilar derecho en las mismas condiciones del anterior de un cerdo con más de dos años y medio que pesó $29 \mathrm{~g}$ y dos fragmentos más de una tibia y un radio de un caprino con cortes de carnicería y manchas como las anteriores descritas. La pérdida de más del $95 \%$ de los huesos de estos tres animales y los cortes en huesos con y sin beneficio cárnico muestran que son desechos tanto del consumo como del despiece del animal sacrificado. 


\begin{tabular}{lllllll}
\hline C-IV & NH & PH g & NMI & ICEn & NHC & NHf \\
\hline BOS & 3 & 392 & 1 & 1,5 & 0 & 3 \\
\hline SUS & 2 & 42 & 1 & 0,7 & 0 & 2 \\
\hline CAP & 2 & 15,5 & 1 & 1 & 0 & 2 \\
\hline CAN & 1 & 20 & 1 & 0,4 & 1 & 0 \\
\hline T. & 8 & 469,5 & 4 & & 1 & 7 \\
\hline
\end{tabular}

Tabla 2.

Número de huesos, peso, número mínimo de individuos, porcentaje de huesos conservados, huesos completos y fragmentados. Corte IV de la Puerta de Córdoba de Carmona.

\section{Corte V. I d.C.- presente}

En $10,2 \mathrm{~m}^{3}$ de volumen excavado en este corte se ha encontrado que el 35,3\% contiene fauna, 3,6 $\mathrm{m}^{3}$, y que dicha fauna está compuesta por especies actualmente domesticadas como en los cortes anteriores. El contenido fósil ha sido de 0,7 individuos $/ \mathrm{m}^{3}$, algo inferior a los anteriores, de los que se han conservado menos del $5 \%$ de los esqueletos. El número de huesos ha sido de 27 y pesaron 902,5 g procedentes de siete ejemplares de vacas, cerdos, caprinos, perros y una pequeña ave cuyos extremos estaban roídos, lo que nos dificulta la identificación. Por la discontinuidades estratigráficas hemos diferenciado dos fases:

Fase I. En la que nos encontramos el nivel 258 datado en el I d.C. y los niveles 257 y 256 datados en el siglo XVII d.C. a los que no hemos considerado en dos fases distintas al encontrar que los huesos de los mismos individuos estaban repartidos entre los tres niveles. El total de huesos ha sido de 26 con un peso de $897,5 \mathrm{~g}$ encontrados en $2,88 \mathrm{~m}^{3}$ y correspondientes a seis ejemplares lo que nos proporciona un contenido fósil de 2,4.

Los restos identificados en el nivel 258 corresponden a varios fragmentos de tibia, escápula, radio y costilla con cortes de despiece con pesos de 104 , $10,150,16,51$ y $10 \mathrm{~g}$; mientras que de las extremidades distales hallamos una falange I con $30 \mathrm{~g}$ cuyas dimensiones muestran a un animal adulto o subadulto (unos tres o cuatro años) de talla pequeña; un fragmento de húmero de un caprino con 19 g; y de un perro encontramos una mandíbula izquierda de similares dimensiones al del corte III con I I g y tres fragmentos de tibia, radio y metápodo con 10, 3 y 2,5g, respectivamente, sin cortes de despiece. De las condiciones de conservación de los huesos con beneficio cárnico de la vaca y del caprino deducimos que son restos de consumo, mientras que el perro fue enterrado completo, sin ser consumido.

En el nivel 257 se han identificado los restos de una vaca, un cerdo con unos dos años y un perro; además de un fragmento tallado y pulido de una aguja para el pelo como el del corte III. Entre los restos tenemos una falange I con $30 \mathrm{~g}$, fragmentos de calcáneo con 64g. y manchas similares a las que se adquieren en las alcantarillas (igual al corte V), de sacro con 93 g, cráneo con 16.5 g, tibia con 68 g y metápodo con $7,5 \mathrm{~g}$, todos con cortes de carnicería. Además, había parte de la mandíbula de cerdo en plena erupción del tercer molar con $22 \mathrm{~g}$, junto a un trozo de occipital con $8,5 \mathrm{~g}$ y otro de calcáneo de 7,5g. Del perro hallamos sólo un tibia casi completa roída en sus extremos que pesó 14,5g.

Del nivel 256 tenemos un hueso tarsiano y tres fragmentos de una extremidad larga que pesaron 13 y $30 \mathrm{~g}$ de una vaca; varios fragmentos de tres húmeros con $69 \mathrm{~g}$, dos derechos y uno izquierdo, correspondientes a dos individuos; de tibia con $17 \mathrm{~g}$, costilla con $2 \mathrm{~g}$, molar tercero con $4,4 \mathrm{~g}$ y extremidades largas de $10 \mathrm{~g}$; también había un fragmento de extremidad de una pequeña ave con 0,1 g. El registro malacológico fue de una valva de Glycymeris glycymeris con $6 \mathrm{~cm}$ de longitud (la medida estándar de un adulto actual) y un fragmento de valva de peregrina.

Fase II. Sólo encontramos un incisivo y un premolar segundo de un cerdo que pesaron 2 y $3 \mathrm{~g}$ hallados en $0,72 \mathrm{~m}^{3}$ excavados en el nivel 234 datado en el siglo XIX-XX que supone un contenido fósil de I,4.

\begin{tabular}{lllllll}
\hline C-V & $\mathrm{NH}$ & $\mathrm{PHg}$ & $\mathrm{NMI}$ & $\mathrm{ICEn}$ & $\mathrm{NHC}$ & $\mathrm{NHf}$ \\
\hline BOS & 10 & 693 & 1 & 1,6 & 3 & 7 \\
\hline SUS & 10 & 149,4 & 3 & 1,5 & 0 & 12 \\
\hline CAP & 1 & 19 & 1 & 0,5 & 0 & 1 \\
\hline CAN & 5 & 41 & 1 & 1,8 & 0 & 5 \\
\hline AVE & 1 & 0,1 & 1 & - & 0 & 1 \\
\hline T. & 27 & 902,5 & 7 & & 3 & 26 \\
\hline
\end{tabular}

\section{Tabla 3.}

Número de huesos, peso, individuos, porcentaje de huesos conservados por individuo, número de huesos completos y fragmentados. Corte $V$ de la Puerta de Córdoba de Carmona.

\section{Interpretación tafonómica y económica del registro faunístico}

La densidad de ejemplares conservados, superior a 0,06 individuos $/ \mathrm{m}^{3}$ de Doñana, nos indica que estos depósitos están originados por un agente biótico, es decir, son restos producidos por un animal o por el hombre. Que ha sido éste último el agente productor no nos queda la menor duda ante la composición faunística y la estructura de edad de los ejemplares observados en los tres cortes, casi todos son animales actualmente domesticados que forman parte de nuestra actual dieta o uso y sacrificados con edades inferiores a los cuatro años, la edad de madurez de este grupo zoológico. De esta conclusión hemos de matizar, siguiendo el criterio energético por el cual consideramos que un animal ha sido o no consumido, el criterio del despiece en función del beneficio cárnico, que si bien el caballo tiene en la actualidad un doble uso (consumo y transporte), los restos del que hemos encontrado en el corte III corresponderían a un enterramiento del animal completo sin pasar por el despiece que se requiere para su consumo; tam- 
bién hemos de mencionar como extraordinario que, según este mismo criterio, el perro encontrado en la fase II del corte III fue consumido como muestra la huella de despiece en la tibia conservada.

La pérdida de más del $95 \%$ de los huesos junto con la alta frecuencia de huesos procedentes de las zonas anatómicas con beneficio cárnico, el 80 \%, que presentan cortes de despiece nos hace pensar que estamos ante los desechos del consumo producidos en las casas. Después fueron arrojados en la zona y enterrados inmediatamente como demuestra el aspecto acerado y sin grietas de los huesos. Un hecho que podemos corroborar, además, con la presencia de vértebras que conservan sus respectivos discos aún cuando no estaban fusionados, lo que implica que los tejidos de conexión estaban frescos cuando los huesos fueron enterrados.

\section{Referencias bibliográficas}

BERNÁLDEZ, E.; 1988. Carta Paleontológica de la provincia de Sevilla I. Anuario Arqueológico de Andalucía, 1986.

BERNÁLDEZ, E. Y A. MAZO; 1989. Hallazgo de restos de un elefante en la gravera de Antiguos Viveros Sevilla. Anuario Arqueológico de Andalucía, 1987.

BERNÁLDEZ, E.; $1996 a$ (en prensa). Vacas y cabras en la Sevilla del siglo XV. Interpretación tafonómica y paleobiológica de macromamíferos terrestres de Doñana. Inferencias ecológicas en los yacimientos arqueológicos del SO. de Andalucía. Universidad de Sevilla.

BERNÁLDEZ, E.; 1996a Bioestratinomía de macromamíferos terrestres de Doñana. Interferencias ecológicas en los yacimientos arqueológicos del S.O. de Andalucía. Universidad de Sevilla.

BEHRENSMEYER, A.K.; 1978. Taphonomic and ecologic information from bone weathering. Paleobiology, 4 (2): I50-162.

DAVIS, S.J.M.; 1989 (1987). La Arqueología de los animales. Ed. Bellaterra, Barcelona.
DRIESCH, VON DEN A.; 1976. A guide to the measurements of Animal Bones from Archaeological Sites. Peabody Museum Bulletin, I. Harvard.

KLEIN, R.G. Y K. CRUZ-URIBE; 1984. The analysis of animal bones from archaeological sites. Chicago. Chicago University Press.

LINDNER, G.; 1983. Moluscos y caracoles de los mares del mundo. Barcelona.

NODDLE, B.; 1974. Ages of epiphyseal closure in feral and domestic goats and age dental eruption. J. Arch.Scie., I: 195-204.

SÁNCHEZ-BELDA, A. Y M.C. SÁNCHEZ; 1987. Razas ovinas españolas. Ministerio de Agricultura, Pesca y Alimentación. Madrid.

SCHMID, E.; 1972. Atlas of Animal Bones. Elsevier Publishing CO. Amsterdam-London-New York

SILVER, I.A.; 1980. La determinación de las edades en los animales domésticos. EN: Ciencia en Arqueología, Ed. Don Brothwell \& E. Briggs: 29|-308.

Nota: Las gráficas aquí reproducidas corrigen las aparecidas en las págs. $8 \mathrm{I}$ del Boletín $\mathrm{PH} \mathrm{n}^{\circ} \mathrm{I}$.

IAPH SECTOR CLIMA Gráficas microclimáticas de las medidas diarias del exterior de la vitrina
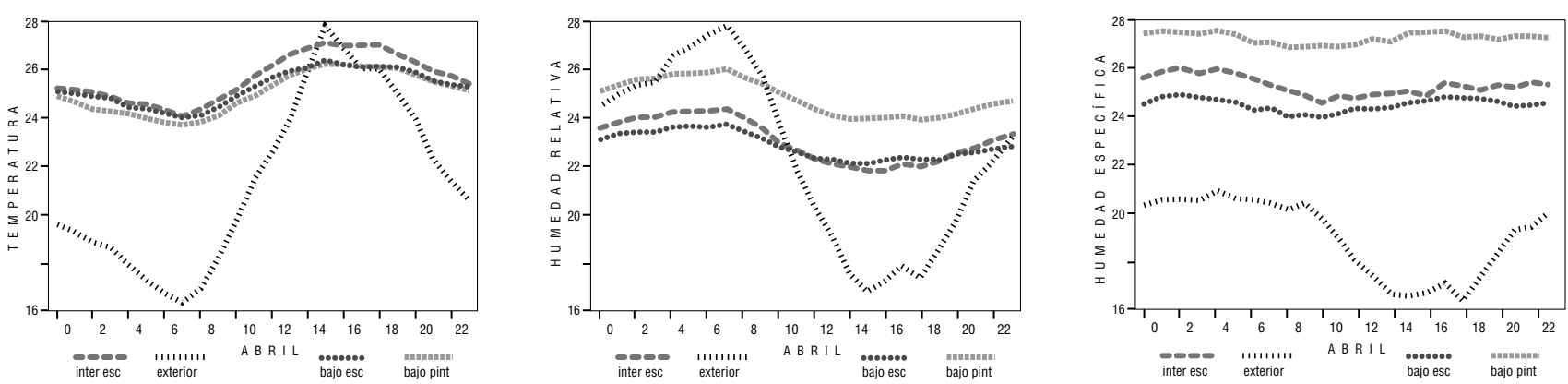

IAPH SECTOR CLIMA Gráficas microclimáticas de las medidas diarias del interior de la vitrina
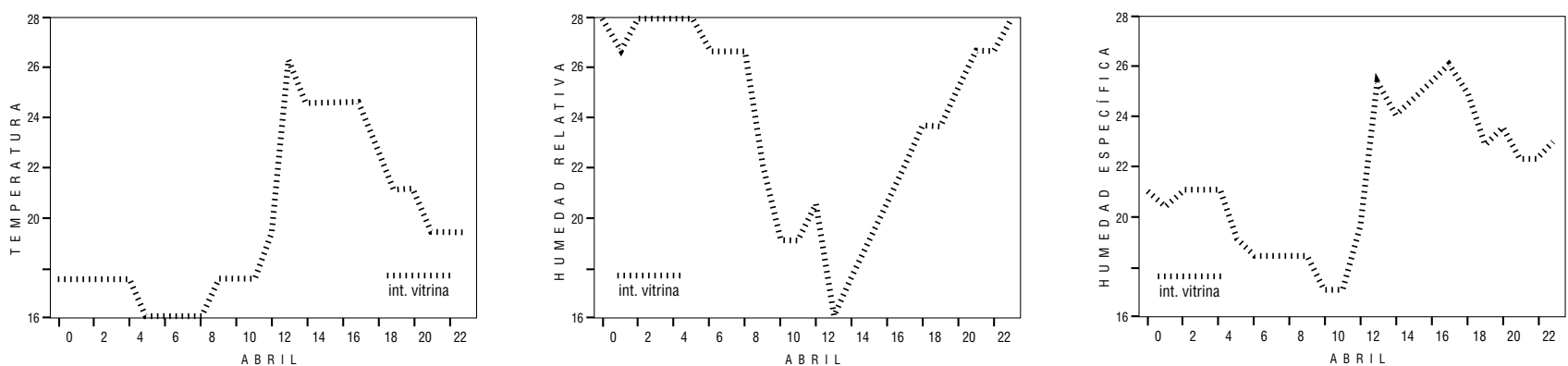